\title{
Synergy in monoclonal antibody neutralization of HIV-1 pseudoviruses and infectious molecular clones
}

\author{
Riccardo Miglietta ${ }^{1,2}$, Claudia Pastori $^{1}$, Assunta Venuti ${ }^{1}$, Christina Ochsenbauer ${ }^{2,3}$ and Lucia Lopalco ${ }^{1 *}$
}

\begin{abstract}
Background: Early events in HIV infection are still poorly understood; virus derived from acute infections, the transmitted/founders IMCs, could provide more reliable information as they represent strains that established HIV infection in vivo, and therefore are investigated to elucidate potentially shared biological features.

Methods: This study examined synergy in neutralization by six monoclonal antibodies targeting different domains in gp120 and gp41 and assayed in pairwise combination against 11 HIV-1 clade B strains, either Env pseudoviruses $(P V, n=5)$ or transmitted/founder infectious molecular clones (T/F IMCs, $n=6)$. Three of the early-infection env tested as PV were juxtaposed with T/F viruses derived from the same three patients, respectively.

Results: All antibodies reaching IC50 were assayed pairwise $(n=50)$. T/F IMCs showed overall lower sensitivity to neutralization by single antibodies than PV, including within the three patient-matched pairs. Remarkably, combination index (Cl) calculated using the Chow and Talalay method indicated synergy $(\mathrm{Cl}<0.9)$ in 42 data sets, and occurred in T/F IMC at similar proportions (15 of 17 antibody-T/F IMC combinations tested) as in pseudoviruses (27 of 33). Cl values indicative of additivity and low-level antagonism were seen in 5 and 3 cases, respectively. Most pairs showed comparable synergic neutralizing effects on both virus groups, with the $4 \mathrm{E} 10+\mathrm{PG} 16$ pair achieving the best synergic effects. Variability in neutralization was mostly observed on pseudovirus isolates, suggesting that factors other than virus isolation technology, such as env conformation, epitope accessibility and antibody concentration, are likely to affect polyclonal neutralization.

Conclusions: The findings from this study suggest that inhibitory activity of bNAbs can be further augmented through appropriate combination, even against viruses representing circulating strains, which are likely to exhibit a less sensitive Tier 2 neutralization phenotype. This notion has important implications for the design and development of anti-Env bNAb-inducing vaccines and polyclonal sera for passive immunization.
\end{abstract}

Keywords: HIV neutralization, T/F-IMC, Pseudovirus, Monoclonal antibody

\section{Introduction}

Neutralizing antibodies to HIV-1 do not generally develop at early stages of infection, and thus usually cannot inhibit HIV-1 amplification and establishment of chronic infection. Selection pressure exerted by host immunity, and the intrinsic ability of HIV-1 to rapidly mutate result in great variability of HIV strains over time, and thus virus isolates from later stages of infection can differ

\footnotetext{
* Correspondence: lopalco.lucia@hsr.it

'Division of Immunology, Transplantation and Infectious Diseases, San Raffaele Scientific Institute, Milan, Italy

Full list of author information is available at the end of the article
}

substantially from the early virus population and in particular from the respective transmitted virus strain(s). Recent approaches utilizing single genome amplification (SGA) of viral sequences from acutely infected patients overcame prior limitations in analyzing the genomes of viruses initiating clinical infection, thereby enabling the identification of transmitted/founder (T/F) HIV env as well as proviral sequences with high reliability, and the subsequent generation of infectious molecular clones (IMC) of T/F HIV-1 [1-3] . Biologic characterization of T/F HIV-1 strains from different clades have begun to reveal distinctions between $\mathrm{T} / \mathrm{F} \mathrm{HIV}-1$ and primary 
isolates from chronic infection as well as laboratoryadapted "reference" virus strains. T/F HIV-1 were found to display an higher glycosylation shield, R5-mediated, T-lymphocyte tropism and, most importantly, relative resistance to antibody neutralization $[1,4,5]$.

In order to develop an effective vaccine able to prevent HIV-1 transmission, it is highly relevant to understand the sensitivity of primary virus strains, including transmitted/founder strains, to humoral defenses. Certain commonly used laboratory-adapted strains and primary HIV isolates are highly neutralization sensitive ("Tier 1" neutralization phenotype) [6] and thus do not adequately reflect the broad spectrum of neutralization observed for primary strains from various clades. The most comprehensive study so far by Montefiori and colleagues [7,8], of 219 Env-pseudotyped viruses assayed in TZM-bl cells $[7,8]$ with sera from 205 HIV-1-infected individuals, highlighted this notion.

We were interested whether pair-wise combinations of potently neutralizing monoclonal antibodies (NAbs) directed against different gp120 and gp41 epitopes had synergistic inhibitory effects against a selection of early infection and transmitted/founder Clade B strains. We posit that information about synergy of HIV-1 antibodies could ultimately be exploited to select epitopes combinations for immunogens that might elicit synergistic bNAbs. We conducted our study employing the widely utilized TZM-bl neutralization assay which was recently validated [9]. We chose four env strains of TZM-bl Tier 2 phenotype cloned from early/acute infections and included in the original Clade B env Reference Panel [10], plus one Tier 1A control (SF162 env) for testing of pseudovirus neutralization of a single round of infection. We juxtaposed three of these pseudoviruses with analysis of their matched clade B full-length transmitted/founder infectious molecular clones (T/F IMCs), together with three additional (Tier 2) clade B T/F IMCs. These bona fide transmitted/founder genome sequences had been derived from acutely infected subjects [1,2], and replicationcompetent IMC representing them had been generated by a novel strategy described previously $[1,2]$. Both sets of viruses were assayed with a panel of potent human neutralizing antibodies directed against distinct envelope epitopes, individually and in pair-wise combination, in order to assess whether synergistic enhancement of inhibition could be achieved.

\section{Materials and methods}

\section{Cells, monoclonal antibodies and HIV-1 viruses}

The $293 \mathrm{~T}$ cell line (CRL-11268) was obtained from the American Type Culture Collection (ATCC, Manassas, VA). The TZM-bl cell line was obtained through the NIH AIDS Research and Reference Reagent Program (NIH ARRRP), Division of AIDS, NIAID, NIH, contributed by John
Kappes and Xiaoyun Wu [8]. The human monoclonal antibodies used (mAb), 4E10, 2 F5, 2G12, b12, PG9, PG16, were obtained from POLYMUN Scientific (Klosterneuburg, AUSTRIA).

Clade B Env-expression plasmids for pseudovirus generation, including pREJO4551 clone 58, AC10.0 clone 29, pCAGGS SF162 gp160 (cat \#10463), pRHPA4259 clone 7, pTHRO4156 clone18, were obtained through the NIH AIDS Research an Reference Reagent Program. (NIH ARRRP as part of the Clade B env pseudovirus panel). The acute env plasmids were generated by Mascola et al. [11] by cloning the gp160 genes from sexually acquired, acute/early infections, in order to facilitate standardized assessments of neutralizing antibody responses. When co-transfected with the env-deleted backbone plasmid pSG3 $\Delta$ env (contributed by. John C. Kappes and Xiaoyun Wu [12]; cat \#11051, included in the Panel) in 293 T cells, these plasmids produce env-pseudotyped viruses that are capable of a single round of infection in TZM-bl cells.

The genomic sequence of full-length transmitted/ founder (T/F) HIV-1 strains were deduced using a mathematical model of HIV-1 sequence evolution in acute clinical infection and an experimental strategy based on single genome amplification (SGA) of plasma vRNA/cDNA, followed by direct sequencing of uncloned SGAs [1,4]. The derivation of bona fide $\mathrm{T} / \mathrm{F}$ infectious molecular clones (IMCs) including pCH040.c/2625, pCH058.c/2960, pCH077.t/2627, pRHPA.c/2635, pTHRO.c/2626, pREJO. c2864 was described previously by Ochsenbauer et al. [2], and T/F IMC are also available through the NIH ARRRP, contributed by John C. Kappes and Christina Ochsenbauer.

SF162 Env has a Tier 1 A phenotype in TZM-bl PV assay; all other strains are described as Tier 2 when tested as Env-PV [Neutralizing Antibody Resources tools, at www.hiv.lanl.gov].

\section{Generation and titration of virus stocks}

$293 \mathrm{~T}$ cell-derived stocks of pseudoviruses and replicationcompetent IMCs were generated by proviral DNA transfection using FuGENE 6, according to the manufacturer's protocol (Promega, Madison, WI). Viral supernatants were harvested $72 \mathrm{~h}$ post-transfection, clarified at $1800 \mathrm{rpm}$ for $20 \mathrm{~min}$, and frozen at $-70^{\circ} \mathrm{C}$. The virus stocks were further analyzed for firefly luciferase expression in the TZM-bl cell line. Four replicates of five-fold dilutions of virus were added to 96 flat-bottomed plate wells containing $1 \times 10^{4}$ TZM-bl cells per well, in 10\% D-MEM growth medium with $7.5 \mathrm{ug} / \mathrm{ml}$ of DEAE-dextran (Sigma) in a final volume of 200ul. After $48 \mathrm{~h}$ incubation at $37^{\circ} \mathrm{C}, 100 \mathrm{uL}$ of culture medium were removed from each well and replaced with $100 \mathrm{uL}$ of Bright-Glo luciferase reagent (Promega). After 2 min incubation, $150 \mathrm{uL}$ of the cell lysate was transferred 
to a 96-well white solid plate and luminescence was measured using a Victor Light 2030 luminometer (Perkin Elmer). Fifty percent infectious dose (ID50) titers were defined as the reciprocal of the virus dilution yielding $50 \%$ positive wells (Reed-Muench calculation).

\section{TZM-bl neutralization assays}

Six 3-fold serial dilutions of antibodies samples (starting from $66 \mathrm{ug} / \mathrm{mL}$ ), were plated in triplicate (96-well flat bottom plate) in 10\% D-MEM growth medium (100 uL/well). 200 TCID50 of each pseudovirus or 20 TCID50 of each T/ F IMC were added to each well in a volume of $100 \mathrm{uL}$ and incubated for $1 \mathrm{~h}$ at $37^{\circ} \mathrm{C}$. TZM-bl cells were then added $\left(1 \times 10^{4} /\right.$ well in a $100 \mathrm{uL}$ volume $)$ in $10 \% \mathrm{D}$-MEM growth medium containing DEAE-dextran (Sigma), at a final concentration of $7.5 \mathrm{ug} / \mathrm{mL}$. Assay controls included replicate wells of TZM-bl cells alone (cell control) and TZM-bl cells with virus (virus control). Following a $48 \mathrm{~h}$ incubation at $37^{\circ} \mathrm{C}, 150 \mathrm{uL}$ of culture medium were removed from each well and replaced with $100 \mathrm{uL}$ of Bright-Glo luciferase reagent (Promega). After a 2-min incubation, 150 $\mathrm{uL}$ of the cell lysate was transferred to a 96-well black solid plate and luminescence was measured using a Victor Light 2030 luminometer (Perkin Elmer). The 50\% inhibitory dose (IC50) was calculated as the concentration of antibody that induced a $50 \%$ reduction in relative luminescence units (RLU) compared to the virus control wells, after subtraction of cell control RLU.

\section{Antibody combinations and synergy calculation}

All antibodies that individually had achieved an IC50 against a given virus strain were combined pairwise with each other to test for combination effects in the inhibition of the respective viruses. The ratio of each antibody concentration in the combinations was not kept constant, but instead followed the dilutions scheme below:

For every mAb pair $(A+B)$, in one column of the 96well plate we plated six 1:3 dilutions of a given antibody (A), starting from one dilution above its IC50. To the same wells we then added the other antibody (B) at a fixed concentration corresponding to its IC50. The same procedure was repeated reciprocally with six three-fold dilutions of the antibody (B) to which antibody (A) was added, plated at the constant concentration representing its IC50. The remainder of the assay was conducted as described above. Each experiment was repeated independently two times.

In order to evaluate the possible synergy between the antibodies, the inhibition data for each combination condition were analyzed using the software CompuSyn [13], which is based on a mathematic model of synergy calculation described by Chou [14,15]; Dr. Chou kindly provided his advice on the applicability of the analysis method to our data set and dilution layout: The "median-effect principle" of Chou's method is based on a linear transformation of the inhibition data. A linear function is then fitted: $\log \left(f_{a} / f_{u}\right)=m \log \left(D / D_{m}\right)$, where $f_{a}=$ fraction affected (i.e., the normalized proportion of inhibited infection); $f_{u}=$ fraction unaffected (i.e., $1-f_{a}$, or the relative residual infectivity); $\mathrm{m}$ is a constant determining the slope of the linear curve; $\mathrm{D}_{\mathrm{m}}$ is the "median effect dose", the equivalent of the half-maximal inhibitory concentration; and D is the concentration of inhibitor yielding a degree of inhibition corresponding to $f_{a}$.

The combination index, $C I=\left(D_{(A B) A} / D_{A}\right)+\left(D_{(A B) B} / D_{B}\right)$ is next calculated from the fitted values of $D$ when inhibitors $A$ or $B$ are used alone $\left(D_{A}\right.$ or $\left.D_{B}\right)$ or as constituents of the combination $\left(\mathrm{D}_{(\mathrm{AB}) \mathrm{A}}\right.$ and $\left.\mathrm{D}_{(\mathrm{AB}) \mathrm{B}}\right)$.

Characteristic values are the following:

When $\mathrm{CI}<0.9$, the two mAbs show synergistic activity; When $0.9 \leq \mathrm{CI} \leq 1.1$, the antibody pair works in additivity:

When CI > 1.1, the two antibodies display antagonism.

As introduced above, 12 individual CI values were calculated for the $2 \times 6$ reciprocal dilutions done for each MAb pairwise combination. From these 12 values, average CI were obtained and the corresponding standard deviations were also calculated.

\section{Results}

In order to assess synergistic enhancement of inhibition by a panel of human neutralizing antibodies with different HIV-1 envelope protein epitope specificity, the study examined six human neutralizing mAbs, recognizing four different env domains; 4E10 and 2 F5 antibodies bind two contiguous epitopes within the gp41 MPER domain [16,17]; 2 G12 antibody recognizes mannose residues located on different glycosides displayed on gp120 surface [18]; b12 antibody specifically interacts with the CD4 binding domain on gp120 [19]; finally, PG9 and PG16 antibodies recognize conformational epitopes on the gp120 V1/V2 loops, binding to various, non-contiguous mannose residues of the glycosidic moiety [20-22].

All monoclonal antibodies were assayed in the TZM-bl neutralization assay [9] against a virus panel including five Clade B pseudoviruses and six infectious molecular clones (IMC), representing Clade B Transmitted/Founder HIV-1 strains [2]. In three cases, both pseudoviruses acute /early env strains and T/F IMC were derived from the same patient; Table 1 summarizes relevant features of monoclonal antibodies and viruses used in the study.

\section{Single antibody neutralization assays}

Prior to conducting combinatorial inhibition assays, all antibodies were first assayed in individual neutralization assays against each virus in the panel, in order to assess 
Table 1 Summary of antibodies and virus strains used in the study.

\begin{tabular}{|c|c|c|c|c|c|c|}
\hline A. mAbs used & \multicolumn{6}{|c|}{ Target on Env } \\
\hline $4 \mathrm{E} 10$ & \multicolumn{6}{|l|}{ MPER* } \\
\hline $2 \mathrm{~F} 5$ & \multicolumn{6}{|l|}{ MPER* } \\
\hline $2 \mathrm{G} 12$ & \multicolumn{6}{|c|}{ V3 glycanst } \\
\hline b12 & \multicolumn{6}{|c|}{ CD4bst } \\
\hline PG9 & \multicolumn{6}{|c|}{ V1N2 loopt } \\
\hline PG16 & \multicolumn{6}{|c|}{ V1N2 loopt } \\
\hline B. env strains used for Pseudovirus & Clade & Subject identifier & Accession Number & Gender & Mode of Transmission & Fiebig Stage $^{b}$ \\
\hline SF162 & B & N.A. & EU123924 & Male & N/A & $\mathrm{Vl}$ \\
\hline AC10.0.29 & B & AC10.0 & AY835446 & Male & $M M^{a}$ & III \\
\hline REJO4541.67 & B & REJO4541 & AY835449 & Male & HSX & $\|$ \\
\hline RHPA4259.7 & B & RHPA4256 & AY835447 & Female & HSX & $\leq \mathrm{V}$ \\
\hline THRO4156.18 & B & THRO4156 & AY835448 & Male & MSM & $\|$ \\
\hline \multicolumn{7}{|l|}{ C. IMC of $T / F$ strains } \\
\hline $\mathrm{CH} 040 . \mathrm{C}$ & B & 700010040 & JN944939 & Male & MSM & $\mathrm{T} / \mathrm{F} \mid \mathrm{MC}^{\mathrm{C}}$ \\
\hline $\mathrm{CH} 058 . \mathrm{C}$ & B & 700010058 & JN944940 & Male & MSM & $T / F I M C^{C}$ \\
\hline $\mathrm{CH} 077 . \mathrm{t}$ & B & 700010077 & JN944941 & Male & MSM & $\mathrm{T} / \mathrm{F} \mid \mathrm{MC}^{\mathrm{C}}$ \\
\hline REJO.C & B & REJO4541 & JN944943 & Male & HSX & $\mathrm{T} / \mathrm{F} I M C^{C}$ \\
\hline RHPA.C & B & RHPA4256 & JN944944 & Female & HSX & $\mathrm{T} / \mathrm{F} I M C^{C}$ \\
\hline THRO.C & B & THRO4156 & JN944947 & Male & MSM & $\mathrm{T} / \mathrm{F} I M C^{C}$ \\
\hline
\end{tabular}

A. Monoclonal antibodies used and respective target epitope on Env; * on gp41 and † on gp120

B-C. Virus used: Pseudovirus (B) and Transmitted/Founders (T/F) IMCS (C).

${ }^{a}$ MSM, men who have sex with men; HSX, heterosexual.

${ }^{\text {b}}$ The stage of HIV-1 infection, as defined by Fiebig et al. [15], at which samples were obtained.

${ }^{\mathrm{C}} \mathrm{T} / \mathrm{F}$ IMCs represent the genomes of the strains that initiated clinical infection in the respective subjects. For detailed description, see C. Ochsenbauer et al., [2].

their respective neutralization potency (IC50) against each PV and IMC HIV strain. As shown in Figure 1, only b12 achieved $50 \%$ neutralization in 10 out of 11 viruses, ( $5 / 5$ pseudoviruses and 5/6 T/F IMC). The Nabs 2 F5 and 4E10 neutralized 7 and 8 viruses, respectively, both neutralized 3/6 T/F IMC, and $4 / 5$ and $5 / 5$ pseudoviruses, respectively, while other antibodies achieved $50 \%$ neutralization in a lower number of isolates. The 2 G12 antibody only achieved $50 \%$ inhibition in $1 / 5$ and $1 / 6$ virus isolates, respectively.

For the three patient-matched pairs (REJO, THRO and RHPA), T/F IMCs generally showed lower sensitivity to neutralization than pseudoviruses with acute/early envs from the same patients, respectively. Among the matched virus pairs, PG16 antibody only neutralized REJO and RHPA but sensitivity to neutralization of the PV and patient-matched T/F IMC was very similar, with IC50 values of comparable magnitude (within 1.5-fold to 2.2-fold range). However, some antibodies failed in 50\% neutralizing the T/F IMC counterparts of the tested PV (e.g. b12 against REJO.c, and 2 F5 against RHPA.c; Figure 1), or the corresponding IC50 value for T/F IMC was by far higher (e.g. >7fold for 4E10 and b12 against THRO.c; Figure 1). These findings are intriguing, however, investigation of the underlying mechanism was outside of the scope and purpose of this study. Representative neutralization curves obtained for pseudoviruses (panels A-B-C) and T/F IMCs (panels D-E-F) from the same subjects (REJO, RHPA and THRO) are shown in Figure 2; neutralization curves were smooth and fulfilled standardized assay acceptance criteria.

\section{Paired neutralization assays}

Once we had assessed neutralization activity of individual antibodies against each virus strains, those antibodies which reached IC50 against a respective virus strain, and thus demonstrated potency, were assayed in pairwise combination against this strain, in order to test for potential synergistic or antagonistic activity. Each antibody pair was tested using reciprocal dilution schemes: the concentration of one antibody was kept constant at its IC50 concentration, while the second antibody was used at 6 three-fold dilutions, starting at one dilution above the IC50, and vice versa. This dilution scheme is a valid method to quantify the so-called Combination Index $(\mathrm{CI})$ as a measure of synergistic, additive or antagonistic effects, utilizing the Chow and Talalay equation illustrated in Material and Methods [14,15]. Compared to the more commonly known matrix-style dilution approach, our approach offers the advantage of utilizing significantly less MAb and assay reagents while generating similarly 

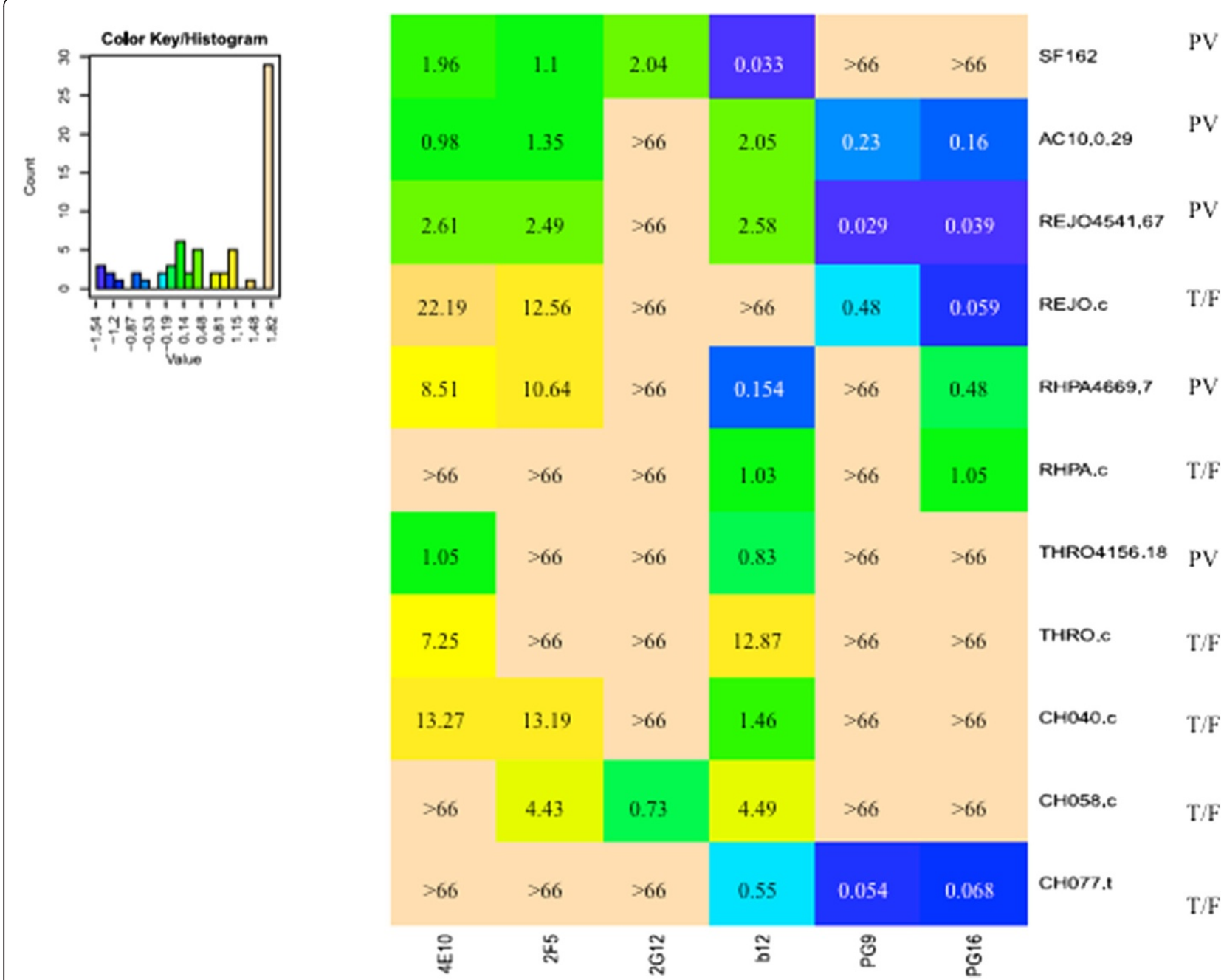

Figure 1 Heat map of the IC50 values obtained with the antibodies tested individually against all virus strains. The $x$ axis of the color key represents the IC50 range in logarithmic scale. Darker cells (blue and green) indicate lower IC50 values and potent neutralization. Lighter cells indicate no detectable or relatively weak neutralization. The non-trasformed IC50 values are indicate in each field and are expressed in $u g / \mathrm{mL}$.

The names of T/F IMCs are provided. Pseudoviruses (PV) are indicated by the respective env clone identifier.

meaningful CI data. CI values for the effect of antibody pairs can range from synergy $(\mathrm{CI}<0.9)$, to additivity $(\mathrm{CI}$ ranging 0.9-1.1) and antagonism $(\mathrm{CI}>1.1)$ [14,15].

In all cases in which antibody combinations were tested against PV $(\mathrm{n}=33)$ and T/F IMC $(\mathrm{n}=17)$, at least $50 \%$ inhibition of infection were observed (data not show). Figure 3 illustrates examples of neutralization curves obtained for three antibody pairs tested against REJO PV which resulted in $\mathrm{CI}$ values indicative of synergistic, additive and antagonistic effects, respectively.

The 12 individual $\mathrm{CI}$ values generated for each $\mathrm{mAb}$ combination against each tested virus strain are illustrated in Figures 4 and 5, and Table 2 summarizes mean CI values and standard deviations for all antibody combinations $(n=50)$, observed against pseudovirus and $T / F$ IMC strains. CI values indicative of synergy $(\mathrm{CI}<0.9)$ were observed in 42 data sets. Of those, 11 synergistic data sets $(\mathrm{n}=8$ in PV group, $\mathrm{n}=3$ in T/F IMC group; data obtained from nine different antibody combinations) with mean $\mathrm{CI}<0.9$ had standard deviations that reached into the range of additivity; in Table 2 they are indicated with hatched light grey shading to distinguish them from the 5 data set for which CI values indicating additivity were obtained (medium grey shading). CI values indicative of low-level antagonism were seen in 3 cases (dark grey shading).

Antibody combination including either 4E10 or 2F5, with the exception of [4E10 + 2F5], displayed synergistic neutralization of all (4E10: $15 / 15)$ or most (2F5: 13/15) tested pseudoviruses and T/F IMC. Combinations of 2F5 antibody with b12 or PG16 resulted in synergistic neutralization of 5 out of 6 (with the sixth one showing borderline additivity), and 4 out of 4 tested virus strains, respectively (Table 2). For T/F IMCs, which had shown 


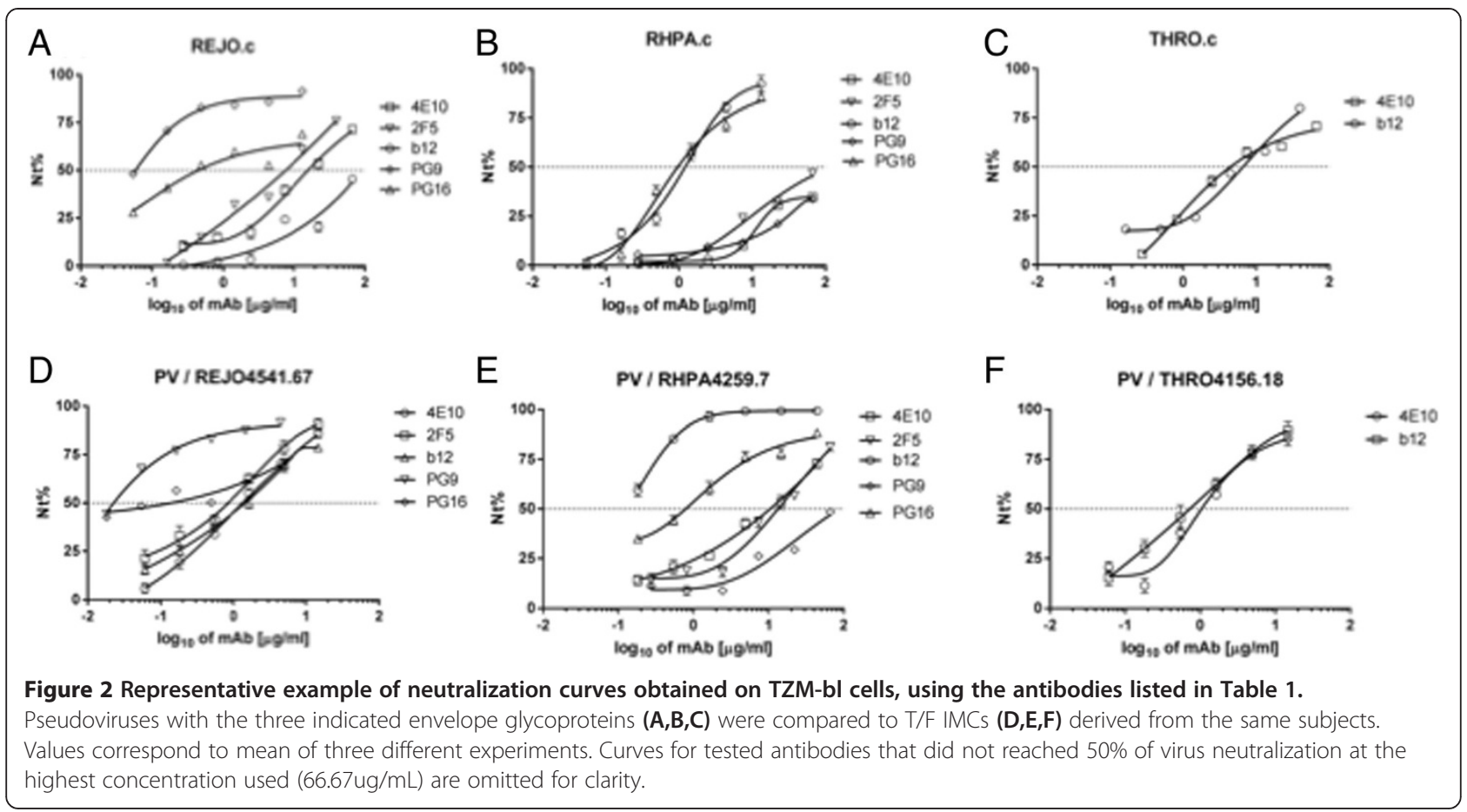

overall lower sensitivity to neutralization by single mAbs than pseudoviruses, fewer $\mathrm{Ab}$ combinations were thus tested $(\mathrm{n}=17)$ than for pseudoviruses $(\mathrm{n}=33)$. Nevertheless, the majority of T/F IMC (15/17) were neutralized synergistically by the tested $\mathrm{Ab}$ combinations; the two exceptions occurred for REJO.c (Table 2 and Figure 4, blue triangles). As illustrated in Figure 4, the mean of all individual $\mathrm{CI}$ values obtained with a given $\mathrm{Ab}$ combination fell into the synergy range for 11/12 Ab combinations tested against T/F IMC, and for 11/13 Ab combinations tested against PV. This finding suggest that IMCs were no less susceptible than pseudoviruses to synergistic activity of antibodies which individually neutralized at least $50 \%$.

Most antibody pairs worked in synergy against all strains they were tested for. However, additivity as well as antagonism were observed for neutralization of both REJO PV and T/F IMC, for SF162 PV, and for AC10.0 PV (borderline additivity for $2 \mathrm{~F} 5+\mathrm{b} 12$ ), (Table 2). From a functional point of view, four pairs of antibodies targeting different domains displayed synergic activity against both pseudoviruses and T/F IMCs (4E10 + b12, 4E10 + PG9, 4E10 + PG16, 2F5 + PG16). Interestingly, as illustrated in Figure 4, all individual $\mathrm{CI}$ values, and not only their respective means, derived for the 4E10 + PG16 combination fell in the range of synergic inhibition of all tested strains (3 PV, 1 T/F IMC). This was also the case for b12+ PG16 against the same three PV strains (Figure 4, circles). In contrast, for other antibody combinations tested against PV, or both PV and T/F IMC, not all 12 CI values for a given virus fell within "synergy" range, despite their respective mean $\mathrm{CI}$ indicating synergy, e.g. $\mathrm{CH} 077 . \mathrm{t} \mathrm{T} / \mathrm{F}$ IMC (orange triangles) with [b12 + PG16] and REJO4551
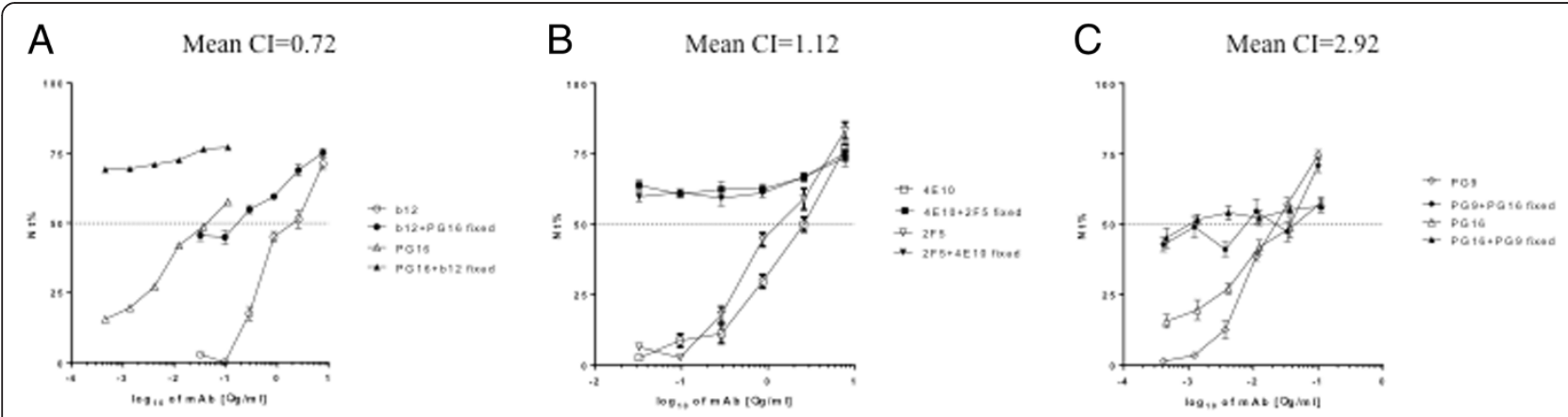

Figure 3 Representative example of synergy (A), additivity (B) and antagonism (C). Neutralization curves and respective $\mathrm{Cl}$ obtained combining 2 antibodies in a non-constant ratio against the PV REJO4541.67. Nt \%: percentage of viral neutralization. 

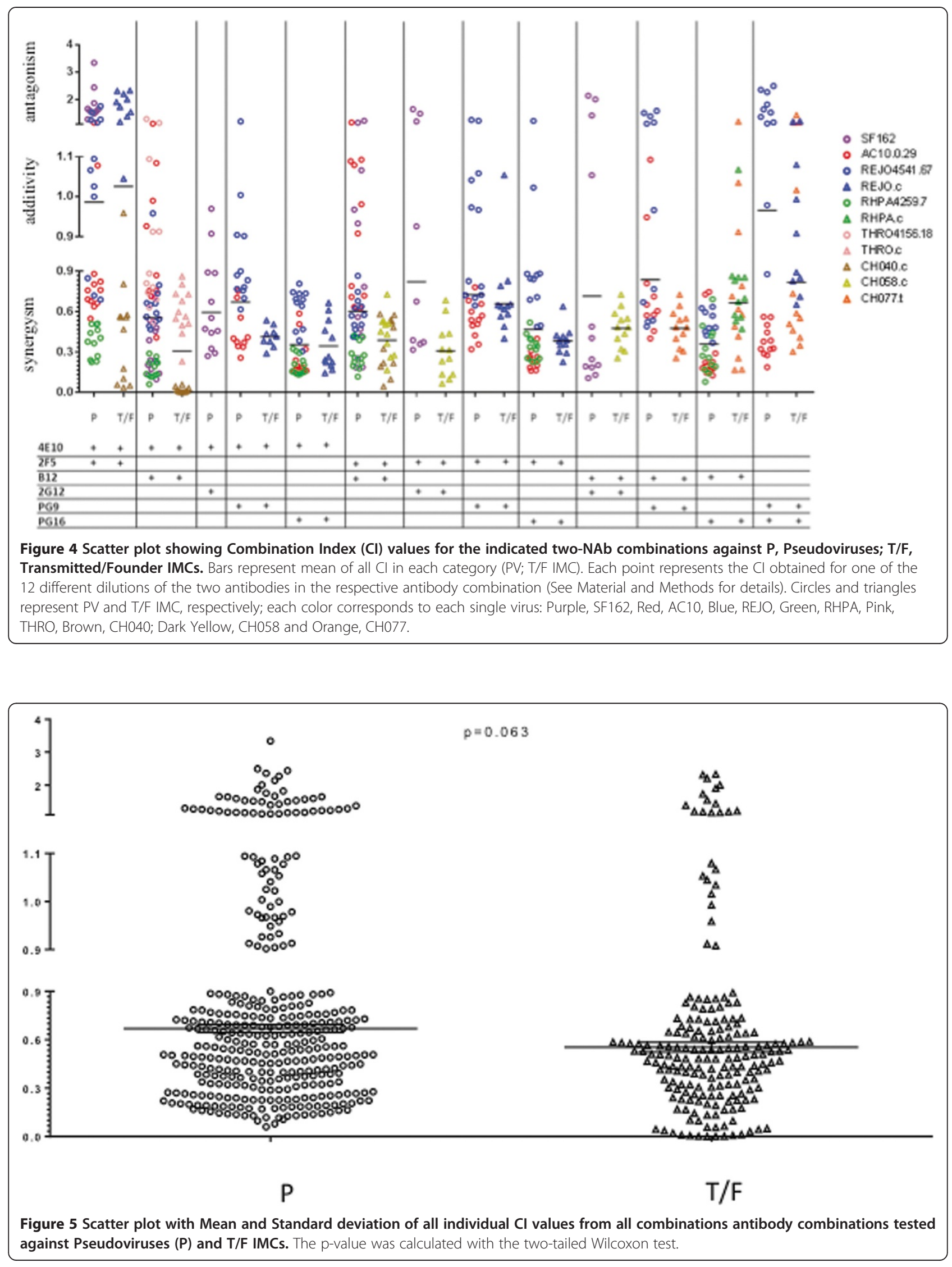
Table 2 Mean and Standard deviation of the Combination Indexes $(\mathrm{CI})$ of antibody pairs assayed against PV and T/F IMC, respectively

\begin{tabular}{|c|c|c|c|c|c|c|c|c|c|c|c|c|c|}
\hline & PSEUDOVIRUS & & & & & T/F IMC & & & & & & Average & \\
\hline & \multicolumn{13}{|c|}{ Combination index } \\
\hline & SF162 & AC10. 0.29 & REJO 4551.67 & RHPA 4259.7 & THRO 4156.18 & REJO.C & RHPA.C & THRO.C & CH040.C & CH058.C & CH077.t & Pseudo & $T / F$ \\
\hline $4 \mathrm{E} 10+2 \mathrm{~F} 5$ & $1.87^{*} \pm 0.59$ & $0.79^{* * *} \pm 0.17$ & $1.12^{* *} \pm 0.29$ & $0.38 \pm 0.11$ & - & $1.76^{*} \pm 0.44$ & - & - & $0.41 \pm 0.3$ & - & - & 1.04 & 1.08 \\
\hline $4 \mathrm{E} 10+\mathrm{b} 12$ & $0.32 \pm 0.18$ & $0.84^{* * *} \pm 0.21$ & $0.64 \pm 0.13$ & $0.18 \pm 0.07$ & $0.87^{* * *} \pm 0.21$ & - & - & $0.6 \pm 0.17$ & $0.016 \pm 0.018$ & - & - & 0.57 & 0.3 \\
\hline $4 \mathrm{E} 10+2 \mathrm{G} 12$ & $0.6 \pm 0.25$ & - & - & - & - & - & - & - & - & - & - & 0.6 & n.d. \\
\hline $4 \mathrm{E} 10+\mathrm{PG} 9$ & - & $0.455 \pm 0.16$ & $0.85^{* * *} \pm 0.15$ & - & - & $0.41 \pm 0.07$ & - & - & - & - & - & 0.65 & 0.41 \\
\hline $4 \mathrm{E} 10+\mathrm{PG} 16$ & - & $0.25 \pm 0.14$ & $0.61 \pm 0.16$ & $0.2 \pm 0.07$ & - & $0.35 \pm 0.17$ & - & - & - & - & - & 0.35 & 0.35 \\
\hline $2 \mathrm{~F} 5+\mathrm{b} 12$ & $0.68^{* * *} \pm 0.37$ & $0.91^{* *} \pm 0.19$ & $0.58 \pm 0.13$ & $0.27 \pm 0.09$ & - & - & - & - & $0.36 \pm 0.16$ & $0.43 \pm 0.15$ & - & 0.61 & 0.39 \\
\hline $2 \mathrm{~F} 5+2 \mathrm{G} 12$ & $0.82^{* * *} \pm 0.49$ & - & - & - & - & - & - & - & - & $0.31 \pm 0.19$ & - & 0.82 & 0.31 \\
\hline $2 F 5+P G 9$ & - & $0.54 \pm 0.13$ & $0.91^{* *} \pm 0.2$ & - & - & $0.66 \pm 0.16$ & - & - & - & - & - & 0.72 & 0.66 \\
\hline $2 \mathrm{~F} 5+\mathrm{PG} 16$ & - & $0.22 \pm 0.05$ & $0.78^{* * *} \pm 0.23$ & $0.34 \pm 0.09$ & - & $0.38 \pm 0.1$ & - & - & - & - & - & 0.44 & 0.38 \\
\hline $\mathrm{b} 12+2 \mathrm{G} 12$ & $0.72^{* * *} \pm 0.72$ & - & - & - & - & - & - & - & - & $0.48 \pm 0.14$ & - & 0.72 & 0.48 \\
\hline b12 + PG9 & - & $0.68 \pm 0.2$ & $1.02^{* *} \pm 0.39$ & - & - & - & - & - & - & - & $0.48 \pm 0.14$ & 0.85 & 0.48 \\
\hline$b 12+P G 16$ & - & $0.29 \pm 0.21$ & $0.72 \pm 0.09$ & $0.31 \pm 0.17$ & - & - & $0.8^{* * *} \pm 0.18$ & - & - & - & $0.61^{* * *} \pm 0.32$ & 0.44 & 0.66 \\
\hline $2 \mathrm{G} 12+\mathrm{PG} 9$ & - & - & - & - & - & - & - & - & - & - & - & n.d & n.d \\
\hline $2 \mathrm{G} 12+\mathrm{PG} 16$ & - & - & - & - & - & - & - & - & - & - & - & n.d & n.d \\
\hline$P G 9+P G 16$ & - & $0.38 \pm 0.11$ & $2.92^{*} \pm 0.54$ & - & - & $0.93^{* *} \pm 0.18$ & - & - & - & - & $0.72^{* * *} \pm 0.36$ & 1.65 & 0.82 \\
\hline
\end{tabular}

*indicates $\mathrm{Cl}$ values that indicate antagonism $(\mathrm{n}=3)$.

***indicates $\mathrm{Cl}$ values that fall in the range of additivity $(n=5)$.

All remaining $\mathrm{Cl}$ values fall only in the range of synergy $(n=34)$.

All remaining $\mathrm{Cl}$ valus fall only in the range of synergy $(\mathrm{n}=34)$.

n.d. stands for not determined. 
pseudovirus (blue circles) with [4E10 + PG9]. Additionally, AC10.0 pseudovirus (red circles) with $2 \mathrm{~F} 5+\mathrm{b} 12$, and REJO PV (blue circles) with 4E10 + 2 F15 are examples of a few additional virus/Ab combinations that resulted in a wide range of $\mathrm{CI}$ values, and for which the mean $\mathrm{CI}$ did not indicate synergy.

Of note, combinations of antibodies recognizing the same overall domain or adjacent epitopes, such as PG9 + PG16 on gp120 or 4E10 + 2F5 on gp41, resulted in CI values ranging from synergy to antagonism, depending on virus strain (Figures 3, 4 and Table 2).

\section{Discussion}

In natural infection, broadly neutralizing antibodies (bNAbs) are generated too late to halt early infection events, and the effectiveness of humoral immunity is further hampered by virus escape in response to developing immune pressure. However, the generation of bNAbs via preventive vaccination could possibly block HIV acquisition. Thus, much effort is being placed on defining optimal immunogens to elicit effective bNAb responses. As the number of identified $\mathrm{T} / \mathrm{F}$ env genes continues to grow, a detailed understanding of whether $\mathrm{T} / \mathrm{F}$ strains may share within or across clades - certain global features affecting neutralization sensitivity will underpin discovery of suitable neutralization targets and, thus, development of a preventive vaccine inducing effective virus neutralization.

The question whether combination of broadly reactive antibodies directed against distinct epitopes may have synergistic, additive or antagonistic effects on neutralization potency has not been adequately addressed. Thus, in this study, a limited scope assessment of such effects on the neutralization of five Env-pseudotyped viruses and six T/F ICMs by six human broadly neutralizing antibodies was performed. All but one of the HIV-1 strains have been ascribed a Tier 2 neutralization phenotype in TZM-bl/PV assays; only SF162 possesses a Tier 1A phenotype (Neutralizing Antibody Resources Tools, at www.hiv.lanl.gov) [23]). To our knowledge, this is the first study to test human bNAbs individually and in pair-wise combinations against a panel of clade $\mathrm{B} T / \mathrm{F}$ viruses; among them, three $\mathrm{T} / \mathrm{F}$ virus strains, REJO.c, RHPA.c and THRO.c, were juxtaposed with pseudoviruses with early infection env genes derived from the same patients, respectively.

Interestingly, the three pseudoviruses and T/F IMCs sharing the nearly identical env sequence, i.e. REJO, RHPA and THRO (with two, two, and one amino acid differences, respectively, between early infection and $\mathrm{T} / \mathrm{F}$ envs; Additional file 1: Figure S1), displayed overall similar patterns of neutralization by single antibodies, however, IC50 values for IMC were generally higher, or not reached (i.e. IC50 > $66 \mu \mathrm{g} / \mathrm{ml}$ ) (Figure 1). For example, the Env proteins in REJO PV and IMC have no substitutions and a shared insertion (Ile) in the b12 epitope, but differ from one another in aa 255 (Ala vs. Val), 2 positions upstream of $\operatorname{Ser}_{257}-\mathrm{Thr}_{258}$ residues which are part of the b12 epitope (Additional file 1: Figure S1); this variation may contribute to the very different IC50s observed for these viruses $(2.58 \mathrm{ug} / \mathrm{mL}$ vs $>66 \mathrm{ug} / \mathrm{mL})$. Similarly, Env proteins in RHPA PV and IMC differ from one another immediately following the $\mathrm{LTRGD}_{437}$ portion of the epitope, and resulted in different IC50 values (0.15 vs $1.08 \mathrm{ug} / \mathrm{mL})$. However, Env in THRO PV and IMC were identical to one another in and around the b12 epitope but still displayed different IC50 (0.83 vs $12.87 \mathrm{ug} / \mathrm{mL}$, respectively). Thus, Env sequence alone cannot fully explain the sensitivity of a specific viruses to a given antibody, nor differences between pseudoviruses and IMCs sharing the same or highly similar env sequence. Of note, previous studies also reported different sensitivity (IC50) of IMC and pseudoviruses with identical env genes to single antibody neutralization, regardless of virus clade [24,25]. In both reports, the pseudoviruses were found to be less sensitive than IMCs to specific mAb neutralization $[24,25]$. However, because of small sample numbers in each study it cannot be ruled out that these results are env-strain specific rather than PV versus IMC specific. In our study including early-infection env PV and T/F IMC, the IMCs generally showed higher IC50 values in single NAb neutralization assays (Figure 1). However, importantly, antibody pair synergy was observed at a higher proportion in IMC than in pseudovirus assays (Figure 4), suggesting that IMCs were as susceptible to synergistic antibody activity as pseudoviruses. Moreover, substantial similarity between IMCs and PV emerged when the distribution of all individual CI values within each group was compared (Figure 5), and no significant differences between IMCs and PV were documented.

Differences in neutralization sensitivity between IMCs and PV could be due to the two genetically distinct proviral backgrounds since IMCs encompass a complete autologous viral genome from which env is expressed in cis under the control of the autologous LTR $[2,4]$. In contrast, pseudoviruses are derived by complementing a common env-defective backbone with heterologous env genes expressed in trans [2,4]. Not surprisingly, other studies have reported that different ratios of backbone and env-plasmids transfected in host cells were found to give rise to pseudovirus particles endowed with different envelope features, such as the proportion of env protein cleavage and the level of gp120 surface expression [26]; such changes in envelope features were found to affect pseudoviruses infectivity, and, possibly, antibody reactivity [26]. Indeed, host cells are known to impact biochemical and structural features of virus particles, e.g. in terms of protein processing, folding and glycosylation patterns [25]. Viruses cultured in PBMC or in primary cells were found 
to be more resistant to antibody neutralization than those obtained from laboratory-adapted cell lines, for example due to a different glycosylation pattern shielding key epitopes and preventing antibody neutralization [24]. However, previous studies investigating structural changes among virus structure or protein composition, failed to associate differences observed in IC50 values or infectivity with any well-defined structural or biochemical feature [26]. In our study, both pseudoviruses and T/F IMCs were produced in $293 \mathrm{~T}$ cells, therefore diversity in antibody sensitivity cannot be ascribed here solely to the effect of host cells. We also strove to minimize other possible sources of variability in neutralization result by choosing a standardized, validated method, the TZM-bl assay [9], to perform all assays. Prior to standardization, unsatisfactory assay equivalency among laboratories had been observed even when reagent batches were shared [27].

As was expected, no single antibody neutralized all virus isolates, neither in the pseudovirus nor the $\mathrm{T} / \mathrm{F}$ IMC group (Figure 1). The b12 antibody, targeting a conserved epitope within the CD4 binding site, achieved $50 \%$ neutralization on most T/F strains (5/6), and all PV strains (5/5). The $2 \mathrm{G} 12$ antibody was poorly reactive against 9 out of 11 viruses, neutralizing only SF162 pseudovirus and CH058 T/F IMC; this finding is in concordance with the absence of critical amino acid residues (N295, N332, S334, N339) of the 2G12 epitope, and glycosylation, in the resistant strains, respectively. PG16 was more reactive than PG9, neutralizing nearly half of virus strains in both panels (Figure 1). Sensitive virus strains in the study do share N156 and N160 glycosylation sites, which are crucial for PG9/PG16 binding (Additional file 1: Figure S1). Conversely, SF162 PV Env, and CH058.c and CH040.c IMC, lacking N160, showed resistance to these mAbs (Figures 1 and 2). THRO PV and IMC were resistant to PG9/PG16 mAbs, albeit the presence of both N156 and N160 glycosylation sites, possibly due to a K178R mutation in the epitope (Additional file 1: Figure S1).

MPER antibodies 4E10 and 2F5 each neutralized 3/6 T/F IMC, and 5/5 (4E10) and 4/5 (2F5) PV, respectively (Figure 2). Of note, IC50 values for both bNAbs differed seven- to ten-fold between patient-matched Env proteins expressed in either the PV or IMC context (IC50 values higher or not reached in IMC) despite identical MPER sequence. The MPER domain in gp41 is usually weakly recognized by neutralizing antibodies in native virus particles [28,29]. Since 2F5 and 4E10 mostly recognize MPER epitopes when gp41 is conformed in pre-hairpin intermediate [28-30], the higher IC50 values obtained against T/F REJO, RHPA and THRO strains may be explained by a more compact and stable conformation of Env expressed in cis from T/F IMCs as compared to their respective pseudovirus counterparts
[31], a feature that could increase binding restriction and result in poor accessibility to antibodies [32].

Since humoral responses to pathogens are usually polyclonal, synergy and antagonism between antibodies may naturally occur. Due to their dimensions, neutralizing antibodies do not cluster on one unique Env molecule within the trimer, but are likely to bind distinct monomers within a single - or within two proximal trimer spikes [30,33]. Electron microscopy and mathematical modeling have not yet determined the spike number required to carry out infection successfully, however, HIV particles are studded with only a low number of spikes (between 4-45), sparsely distributed on the envelope membrane [34]. Therefore, synergy and antagonism would result from the interaction of two or more antibodies with a population of molecular targets, where each single virus particle can carry a number of trimer spikes as well as Env dimers or monomers [33-35], and it cannot be readily assumed that two antibodies would have synergistic or antagonistic effects because they were bound to the same Env molecule. Due to the inherit variability of the envelope protein, a relevant question is whether in the in vivo context the presence of prolonged Nabs activity may play a role in modulating evolution of the disease. Although it is worth mentioning that Nabs have been associated with control of the disease in Long-Term Non-Progressor subjects, where an equilibrium has been established between virus and host, we cannot exclude that over time mutations occurring within the envelope can affect neutralizing activity thus resulting in an antagonism rather then synergy. This latter situation could occur when the patients' clinical status changes to rapid progressors, thus loosing the previously established equilibrium. In this regard, the different density level of envelope spike could play a crucial role as well. The low density of envelope spikes, a distinguishing feature when compared with viruses to which protective neutralizing antibody responses are consistently raised, directly impedes bivalent binding by IgG antibodies. The result is a minimization of avidity, normally used by antibodies to achieve high affinity binding and potent neutralization, thereby expanding the range of mutations that allow HIV to evade antibodies. Understanding limitations to avidity may be essential to establish whether specific antibodies combination can differentially modulate their activity, in particular upon variability on the density of envelope spike during the course of chronic infection.

Not all antibody combinations were tested against all PV and T/F IMC strains since not every antibody had reached IC50 individually. In all cases in which antibody combinations were assayed $(\mathrm{n}=33$ for PV; $\mathrm{n}=17$ for T/F IMC), inhibition levels of at least $50 \%$ were reached. Remarkably, synergy was observed in 42 out of 50 assays. 
CI values indicative of additivity were seen in 5 cases (one with T/F ICMs; four with pseudovirus assays). Low level antagonism was observed in three assays (one with $\mathrm{T} / \mathrm{F}$ IMC, two with $\mathrm{PV}$, respectively) and involved antibody combinations 2F5 + 4E10, and PG9 + PG16 which target related epitopes (Figures 2, 3, 4, Table 2). Nearly all antibody pairs achieved synergistic inhibition of both pseudoviruses and T/F IMCs, respectively, with a few and possibly virus-strain specific exceptions (Table 2). Findings from the bNAb pair assays, thus, suggest that synergy usually occurs when antibodies targeting different env domains were involved (e.g. 4E10 - or 2F5 - with b12 or with PG16). In other words, association of two suitable antibodies could induce a favourable conformational change, when binding the same monomer in a trimer or even when binding different monomers, therefore creating favourable conditions for synergic activity. From this point of view, synergy between b12 and MPERtargeting antibodies is not surprising, because CD4 binding takes usually place before gp41 exposure and promotes Env refolding into the intermediate, extended conformation $[29,36]$. Similarly, b12 binding could enhance accessibility of 4E10 (or 2F5) antibodies to MPER domain by inducing suitable conformational changes involving both gp120 and gp41 glycoproteins [30,37,38].

Combinations of PG9 + PG16 and the 2F5 + 4E10 antibodies, with members of each pair targeting overlapping or adjacent epitopes, were tested as controls. Surprisingly, their mean CI values ranged from synergy to antagonism depending on virus isolates (Table 2). In some cases all 12 individual $\mathrm{CI}$ values for each bNAb pair/ virus combination (Figure 4) fell into only one category (e.g. for 4E10 + 2F5 vs RHPA PV), while in others the individual $\mathrm{CI}$ values differed over a wide range depending on NAb concentrations (e.g. synergy for 4E10 + 2F5 versus REJO PV). While antagonism observed with the PG9 + PG16 pair may be explained by steric hindrance or target competition, since both of them bind V1-V2 loops of gp120 or quaternary structures exposed on the top of the gp120 trimer $[39,40]$, it is noteworthy that antagonism was seen in only one out of four tested virus strains. The PG9/PG16 binding site determinants on gp120, and Env trimers, are not fully resolved; the N160 glycosylation site, shared by most HIV isolates, is one unique feature precisely attributed to both binding sites, and its mutations are known to affect PG9-PG16 neutralization [41]. All viruses tested in the study share N160 glycosylation site within their gp120 sequences (see Additional file 1: Figure S1), however they differ in the amino acid positions in the adjacent contact sites and displayed different neutralization sensitivity to PG9 and PG16, possibly because not all gp120 molecules and Env trimers could effectively bind PG16 and PG9. In the case where PG9 and PG16 neutralize individually, but their activity is antagonistically affected in combination it is possible that the PG9 and PG16 pair compete for the same binding site when both present, and thus causing antagonism [34] .

The 2F5 and 4E10 antibodies recognize two contiguous, linear epitopes along MPER, which are especially but not exclusively - accessible in pre-fusion gp41, i.e. the pre-hairpin intermediate. Differently from PG9-PG16, the two MPER epitopes are close, but not overlapping; moreover, 2F5 and 4E10 antibodies target epitopes which are made accessible on different conformations of gp41 [36] therefore, their binding may not be competitive under some conditions [42], and in an Env strain dependent manner. Due to the nature of the epitope conformation and to MPER refolding, the 4E10 epitope may be accessible on native gp41 and throughout gp41 refolding, while the 2F5 epitope is accessible only during early phases of hairpin formation [36]. In addition, mutations involving the CDR-H3 region in 2F5 and 4E10 are known to reduce their interaction with lipids without altering epitope binding, but make these antibodies non-neutralizing [28]. The notion of the better and more prolonged accessibility of the 4E10 epitope versus the 2F5 epitope was supported by studies in which 4 E10 showed a broader neutralizing activity than 2 F5.

Due to misfolding, symmetry within Env trimers may be disturbed, making MPER epitopes - as well as any other Env epitope - more easily accessible to antibodies [43]. Furthermore, 2F5 antibodies representing different isotypes (IgA2 and IgG1) displayed synergic neutralizing activity even though they were directed against the same 2F5 epitope, probably by accessing and blocking $2 \mathrm{~F} 5$ epitopes on distinct gp41 molecules within or between trimers [44]. Hence, the 4E10-2F5 range of synergy-additivityantagonism observed in the study may result from binding to individual monomers in single or multiple trimers as well as from strong membrane interactions, with unexpected effects on virus infectivity [12,17,28,36,45-47].

In future work it will be of interest to explore whether antibodies that individually are poorly inhibitory and fail to reach IC50 could nevertheless be more potent in combination, due to synergic effects. To further validate the findings from our study that bNAb synergy may be a rather ubiquitous occurrence and thus may be harnessed to inhibit HIV-1 infection, it would be ideal to test a larger panel of circulating HIV-1 strains against additional bNAbs from the ever-growing reservoir. The recently described multi-clade Global Panel of 12 Env clones from the Neutralization Serotype Discovery Project (NSDP) was shown to represent the continuum of neutralization phenotypes observed for globally circulating HIV-1 strains [7]. Thus, testing for bNAb synergy against the Env Global Panel would be highly relevant and timely to gain a deeper understanding of the prevalence and potential of synergic effects on neutralization. 
In conclusion, we submit that immune strategies eliciting synergic antibody responses have the potential to augment inhibition of transmission and early virus infection, provided that polyclonal responses are employed and that their synergic potential can be fully exploited. Although many open questions remain regarding bNAb synergy, exploiting synergy between more easily inducible individual broadly neutralizing antibodies with more limited potency holds promise for effective vaccination strategies.

\section{Conclusion}

IMCs of HIV-1 strains which have established clinical infection in vivo afford the opportunity to elucidate relevant biological features of transmitted/founder HIV-1. So far, vaccine approaches have failed to elicit the most potent broadly neutralizing antibodies (bNAbs). In this study, we investigated whether pairwise combination of six bNAbs may result in synergic effects on the neutralization of six T/F IMC strains, and pseudoviruses with five env strains, thus augmenting inhibitory potential of individual bNAbs. Three of the early-infection envs tested as PV were juxtaposed with $T / F$ viruses derived from the same three patients, respectively.

Albeit we observed generally higher resistance of $\mathrm{T} / \mathrm{F}$ IMCs to neutralization as compared to the tested pseudoviruses, a similar degree of synergistic activity of antibody pairs was achieved with both virus groups, irrespective of the presentation of Env on virions following expression in cis or in trans. Immune strategies eliciting antibody responses with epitope specificities that favor synergic activity, thus, hold promise to improve inhibition of transmitted/founder and early infection virus strains. Not unexpectedly, we observed that the nature of epitopes targeted by Nabs in paired assays affected the synergic versus additive or antagonistic effects. In our limited-scope study, the 4E10 and PG16 antibodies, when paired, showed optimal synergic activity on both T/F IMC and early-infection env PV HIV-1.

The results from this study suggest that considering the concept of synergy between more easily inducible individual broadly neutralizing antibodies which may have more limited individual potency may be useful for designing vaccines and passive immunization approaches.

\section{Additional file}

Additional file 1: Gp160 amino acid sequence alignments of env genes used for pseudotyping and from Transmitted/Founder viruses derived from the same subjects, A) REJO4541, B) RHPA4259, C) THRO4156, respectively.

\section{Competing interests}

The authors declare that they have no competing interests.

\section{Authors' contributions}

Authors RM, CP, AV and LL contributed to conception and design of the study and acquisition of data. All authors contributed to analysis of data. All authors contributed in drafting and revising the manuscript, and approved the final version.

\section{Acknowledgement}

This work was supported by the Italian Ministry of Health (grant $40 \mathrm{H} 15)$ and by the UAB Center for AIDS Research (NIH/NIAID P30-Al-27767) Virology Core at the University of Alabama at Birmingham (UAB).

We thank NIH AIDS Research and Reference Reagent Program (NIH ARRRP) for providing us the following reagents TZM-bl cells (ARRRP Cat. Number 8129) were contributed by J. C. Kappes, X. Wu, and Tranzyme. The panel of T/F HIV-1 IMC was contributed by J.C. Kappes and C. Ochsenbauer (ARRRP Cat. Number 11919). A special thank to T.C. Chou for his generous advice on the applicability of the analysis method to our data set.

\section{Author details}

'Division of Immunology, Transplantation and Infectious Diseases, San Raffaele Scientific Institute, Milan, Italy. ${ }^{2}$ Department of Medicine, University of Alabama at Birmingham, Birmingham, AL, USA. ${ }^{3}$ CFAR, University of Alabama at Birmingham, Birmingham, AL, USA.

Received: 19 August 2014 Accepted: 26 November 2014

Published online: 13 December 2014

\section{References}

1. Salazar-Gonzalez JF, Salazar MG, Keele BF, Learn GH, Giorgi EE, Li H, Decker JM, Wang S, Baalwa J, Kraus MH, Parrish NF, Shaw KS, Guffey MB, Bar KJ, Davis KL, Ochsenbauer-Jambor C, Kappes JC, Saag MS, Cohen MS, Mulenga J, Derdeyn CA, Allen S, Hunter E, Markowitz M, Hraber P, Perelson AS, Bhattacharya T, Haynes BF, Korber BT, Hahn BH, Shaw GM: Genetic identity, biological phenotype, and evolutionary pathways of transmitted/ founder viruses in acute and early HIV-1 infection. J Exp Med 2009, 2009(206):1273-1289.

2. Ochsenbauer C, Edmonds TG, Ding H, Keele BF, Decker J, Salazar MG, Salazar-Gonzalez JF, Shattock R, Haynes BF, Shaw GM, Hahn BH, Kappes JC: Generation of transmitted/founder HIV-1 infectious molecular clones and characterization of their replication capacity in CD4 T lymphocytes and monocyte-derived macrophages. J Virol 2012, 86:2715-2728.

3. Baalwa J, Wang S, Parrish NF, Decker JM, Keele BF, Learn GH, Yue L, Ruzagira E, Ssemwanga D, Kamali A, Amornkul PN, Price MA, Kappes JC, Karita E, Kaleebu P, Sanders E, Gilmour J, Allen S, Hunter E, Montefiori DC, Haynes BF, Cormier E, Hahn BH, Shaw GM: Molecular identification, cloning and characterization of transmitted/founder HIV-1 subtype A, D and A/D infectious molecular clones. Virology 2013, 436:33-48.

4. Keele BF, Giorgi EE, Salazar-Gonzalez JF, Decker JM, Pham KT, Salazar MG, Sun C, Grayson T, Wang S, Li H, Wei X, Jiang C, Kirchherr JL, Gao F, Anderson JA, Ping LH, Swanstrom R, Tomaras GD, Blattner WA, Goepfert PA, Kilby JM, Saag MS, Delwart EL, Busch MP, Cohen MS, Montefiori DC, Haynes BF, Gaschen B, Athreya GS, Lee HY, Wood N, Seoighe C, Perelson AS, Bhattacharya T, Korber BT, Hahn BH, Shaw GM: Identification and characterization of transmitted and early founder virus envelopes in primary HIV-1 infection. Proc Natl Acad Sci U S A 2008, 105:7552-7557.

5. Edmonds TG, Ding H, Yuan X, Wei Q, Smith KS, Conway JA, Wieczorek L, Brown B, Polonis V, West JT, Montefiori DC, Kappes JC, Ochsenbauer C: Replication competent molecular clones of HIV-1 expressing Renilla luciferase facilitate the analysis of antibody inhibition in PBMC. Virology 2010, 408:1-13.

6. Seaman MS, Janes H, Hawkins N, Grandpre LE, Devoy C, Giri A, Coffey RT, Harris L, Wood B, Daniels MG, Bhattacharya T, Lapedes A, Polonis VR, McCutchan FE, Gilbert PB, Self SG, Korber BT, Montefiori DC, Mascola JR: Tiered categorization of a diverse panel of HIV-1 Env pseudoviruses for assessment of neutralizing antibodies. J Virol 2010, 2010(84):1439-1452.

7. deCamp A, Hraber P, Bailer RT, Seaman MS, Ochsenbauer C, Kappes J, Gottardo R, Edlefsen P, Self S, Tang H, Greene K, Gao H, Daniell X, Sarzotti-Kelsoe M, Gorny MK, Zolla-Pazner S, LaBranche CC, Mascola JR, Korber BT, Montefiori DC: Global panel of HIV-1 Env reference strains for standardized assessments of vaccine-elicited neutralizing antibodies. J Virol 2014, 88:2489-2507.

8. Wei X, Decker JM, Liu H, Zhang Z, Arani RB, Kilby JM, Saag MS, Wu X, Shaw GM, Kappes JC: Emergence of resistant human immunodeficiency virus type 1 in 
patients receiving fusion inhibitor (T-20) monotherapy. Antimicrob Agents Chemother 2002, 46:1896-1905.

9. Sarzotti-Kelsoe M, Bailer RT, Turk E, Lin CL, Bilska M, Greene KM, Gao H, Todd CA, Ozaki DA, Seaman MS, Mascola JR, Montefiori DC: Optimization and validation of the TZM-bl assay for standardized assessments of neutralizing antibodies against HIV-1. J Immunol Methods 2014, 409:147-160.

10. Li M, Gao F, Mascola JR, Stamatatos L, Polonis VR, Koutsoukos M, Voss G, Goepfert P, Gilbert P, Greene KM, Bilska M, Kothe DL, Salazar-Gonzalez JF, Wei X, Decker JM, Hahn BH, Montefiori DC: Human immunodeficiency virus type 1 env clones from acute and early subtype B infections for standardized assessments of vaccine-elicited neutralizing antibodies. J Viro/ 2005, 79:10108-10125.

11. Mascola JR, D'Souza P, Gilbert P, Hahn BH, Haigwood NL, Morris L, Petropoulos CJ, Polonis VR, Sarzotti M, Montefiori DC: Recommendations for the design and use of standard virus panels to assess neutralizing antibody responses elicited by candidate human immunodeficiency virus type 1 vaccines. J Virol 2005, 79:10103-10107.

12. Dennison SM, Stewart SM, Stempel KC, Liao HX, Haynes BF, Alam SM: Stable docking of neutralizing human immunodeficiency virus type 1 gp41 membrane-proximal external region monoclonal antibodies 2F5 and $4 \mathrm{E} 10$ is dependent on the membrane immersion depth of their epitope regions. J Virol 2009, 83:10211-10223.

13. Chou TC, Martin N, CompuSyn for Drug Combinations: PC Software and User's Guide: A Computer Program for Quantitation of Synergism and Antagonism in Drug Combinations, and the Determination of IC50 and ED50 and LD50 Values. Paramus, (NJ), USA: ComboSyn Inc; 2005

14. Chou TC: Theoretical basis, experimental design, and computerized simulation of synergism and antagonism in drug combination studies. Pharmacol Rev 2006, 58:621-681.

15. Chou TC, Talalay P: Quantitative analysis of dose-effect relationships: the combined effects of multiple drugs or enzyme inhibitors. Adv Enzyme Regul 1984, 22:27-55.

16. Montero M, van Houten NE, Wang X, Scott JK: The membrane-proximal external region of the human immunodeficiency virus type 1 envelope: dominant site of antibody neutralization and target for vaccine design. Microbiol Mol Biol Rev 2008, 72:54-84.

17. Song L, Sun ZY, Coleman KE, Zwick MB, Gach JS, Wang JH, Reinherz EL, Wagner G, Kim M: Broadly neutralizing anti-HIV-1 antibodies disrupt a hinge-related function of gp41 at the membrane interface. Proc Natl Acad Sci U S A 2009, 106:9057-9062.

18. Sanders RW, Venturi M, Schiffner L, Kalyanaraman R, Katinger H, Lloyd KO, Kwong PD, Moore JP: The mannose-dependent epitope for neutralizing antibody $2 \mathrm{G} 12$ on human immunodeficiency virus type 1 glycoprotein gp120. J Virol 2002, 76:7293-7305.

19. Saphire EO, Parren PW, Pantophlet R, Zwick MB, Morris GM, Rudd PM, Dwek RA, Stanfield RL, Burton DR, Wilson IA: Crystal structure of a neutralizing human IGG against HIV-1: a template for vaccine design. Science 2001, 293:1155-1159.

20. McLellan JS, Pancera M, Carrico C, Gorman J, Julien JP, Khayat R, Louder R, Pejchal R, Sastry M, Dai K, O'Dell S, Patel N, Shahzad-ul-Hussan S, Yang Y, Zhang B, Zhou T, Zhu J, Boyington JC, Chuang GY, Diwanji D, Georgiev I, Kwon YD, Lee D, Louder MK, Moquin S, Schmidt SD, Yang ZY, Bonsignori M, Crump JA, Kapiga SH, Sam NE, Haynes BF, Burton DR, Koff WC, Walker LM, Phogat S, Wyatt R, Orwenyo J, Wang LX, Arthos J, Bewley CA, Mascola JR, Nabel GJ, Schief WR, Ward AB, Wilson IA, Kwong PD: Structure of HIV-1 gp120 V1/ V2 domain with broadly neutralizing antibody PG9. Nature 2011, 480:336-343.

21. Doores KJ, Bonomelli C, Harvey DJ, Vasiljevic S, Dwek RA, Burton DR, Crispin M, Scanlan CN: Envelope glycans of immunodeficiency virions are almost entirely oligomannose antigens. Proc Natl Acad Sci U S A 2010, 107:13800-13805.

22. Doores KJ, Burton DR: Variable loop glycan dependency of the broad and potent HIV-1-neutralizing antibodies PG9 and PG16. J Virol 2010, 84:10510-10521.

23. Los Alamos National Laboratory. Neutralizing Antibody Resources Tools 2014. posting date http://www.hiv.lanl.gov/content/immunology. [Online].

24. Louder MK, Sambor A, Chertova E, Hunte T, Barrett S, Ojong F, Sanders-Buell E, Zolla-Pazner S, McCutchan FE, Roser JD, Gabuzda D, Lifson JD, Mascola JR: HIV-1 envelope pseudotyped viral vectors and infectious molecular clones expressing the same envelope glycoprotein have a similar neutralization phenotype, but culture in peripheral blood mononuclear cells is associated with decreased neutralization sensitivity. Virology 2005, 339:226-238.
25. Provine NM, Cortez V, Chohan V, Overbaugh J: The neutralization sensitivity of viruses representing human immunodeficiency virus type 1 variants of diverse subtypes from early in infection is dependent on producer cell, as well as characteristics of the specific antibody and envelope variant. Virology 2012, 427:25-33.

26. Provine NM, Puryear WB, Wu X, Overbaugh J, Haigwood NL: The infectious molecular clone and pseudotyped virus models of human immunodeficiency virus type 1 exhibit significant differences in virion composition with only moderate differences in infectivity and inhibition sensitivity. J Virol 2009, 83:9002-9007.

27. Todd CA, Greene KM, Yu X, Ozaki DA, Gao H, Huang Y, Wang M, Li G, Brown R, Wood B, D'Souza MP, Gilbert P, Montefiori DC, Sarzotti-Kelsoe M: Development and implementation of an international proficiency testing program for a neutralizing antibody assay for HIV-1 in TZM-bl cells. J Immunol Methods 2012, 375:57-67.

28. Chen J, Frey G, Peng H, Rits-Volloch S, Garrity J, Seaman MS, Chen B: Mechanism of HIV-1 Neutralization by Antibodies Targeting a Membrane-Proximal Region of gp41. J Virol 2014, 88:1249-1258.

29. Julien JP, Cupo A, Sok D, Stanfield RL, Lyumkis D, Deller MC, Klasse PJ, Burton DR, Sanders RW, Moore JP, Ward AB, Wilson IA: Crystal structure of a soluble cleaved HIV-1 envelope trimer. Science 2013, 342:1477-1483.

30. Pejchal R, Wilson IA: Structure-based vaccine design in HIV: blind men and the elephant? Curr Pharm Des 2010, 16:3744-3753.

31. Go EP, Hewawasam G, Liao HX, Chen H, Ping LH, Anderson JA, Hua DC, Haynes BF, Desaire H: Characterization of glycosylation profiles of HIV-1 transmitted/founder envelopes by mass spectrometry. J Virol 2011, 85:8270-8284.

32. Reardon PN, Sage H, Dennison SM, Martin JW, Donald BR, Alam SM, Haynes BF, Spicer LD: Structure of an HIV-1-neutralizing antibody target, the lipid-bound gp41 envelope membrane proximal region trimer. Proc Natl Acad Sci U S A 2014, 111:1391-1396.

33. Klasse PJ: The molecular basis of HIV entry. Cell Microbiol 2012, 14:1183-1192.

34. Klein JS, Bjorkman PJ: Few and Far Between: How HIV May Be Evading Antibody Avidity. PLoS Pathog 2010, 6:e1000908.

35. Klasse PJ: Modeling how many envelope glycoprotein trimers per virion participate in human immunodeficiency virus infectivity and its neutralization by antibody. Virology 2007, 369:245-262.

36. Buzon V, Natrajan G, Schibli D, Campelo F, Kozlov MM, Weissenhorn W: Crystal structure of HIV-1 gp41 including both fusion peptide and membrane proximal external regions. PLoS Pathog 2010, 6:e1000880.

37. Zolla-Pazner S: Identifying epitopes of HIV-1 that induce protective antibodies. Nat Rev Immunol 2004, 4:199-210.

38. Wilen CB, Tilton JC, Doms RW: Molecular mechanisms of HIV entry. Adv Exp Med Biol 2012, 726:223-242

39. Pancera M, McLellan JS, Wu X, Zhu J, Changela A, Schmidt SD, Yang Y, Zhou T, Phogat S, Mascola JR, Kwong PD: Crystal structure of PG16 and chimeric dissection with somatically related PG9: structure-function analysis of two quaternary-specific antibodies that effectively neutralize HIV-1. J Virol 2010, 84:8098-8110.

40. Pejchal R, Walker LM, Stanfield RL, Phogat SK, Koff WC, Poignard P, Burton DR, Wilson IA: Structure and function of broadly reactive antibody PG16 revea an $\mathrm{H} 3$ subdomain that mediates potent neutralization of HIV-1. Proc Natl Acad Sci U S A 2010, 107:11483-11488

41. Davenport TM, Friend D, Ellingson K, Xu H, Caldwell Z, Sellhorn G, Kraft Z, Strong RK, Stamatatos L: Binding interactions between soluble HIV envelope glycoproteins and quaternary-structure-specific monoclonal antibodies PG9 and PG16. J Virol 2011, 85:7095-7107.

42. Frey G, Peng H, Rits-Volloch S, Morelli M, Cheng Y, Chen B: A fusionintermediate state of HIV-1 gp41 targeted by broadly neutralizing antibodies. Proc Natl Acad Sci U S A 2008, 105:3739-3744.

43. Sabin C, Corti D, Buzon V, Seaman MS, Lutje Hulsik D, Hinz A, Vanzetta F, Agatic G, Silacci C, Mainetti L, Scarlatti G, Sallusto F, Weiss R, Lanzavecchia A, Weissenhorn W: Crystal structure and size-dependent neutralization properties of HK20, a human monoclonal antibody binding to the highly conserved heptad repeat 1 of gp41. PLoS Pathog 2010, 6:e1001195.

44. Tudor D, Yu H, Maupetit J, Drillet AS, Bouceba T, Schwartz-Cornil I, Lopalco L, Tuffery P, Bomsel M: Isotype modulates epitope specificity, affinity, and antiviral activities of anti-HIV-1 human broadly neutralizing 2F5 antibody. Proc Natl Acad Sci U S A 2012, 109:12680-12685.

45. Sun ZY, Oh KJ, Kim M, Yu J, Brusic V, Song L, Qiao Z, Wang JH, Wagner G, Reinherz EL: HIV-1 broadly neutralizing antibody extracts its epitope from 
a kinked gp41 ectodomain region on the viral membrane. Immunity 2008, 28:52-63.

46. Alam SM, Morelli M, Dennison SM, Liao HX, Zhang R, Xia SM, Rits-Volloch S, Sun L, Harrison SC, Haynes BF, Chen B: Role of HIV membrane in neutralization by two broadly neutralizing antibodies. Proc Natl Acad Sci U S A 2009, 106:20234-20239.

47. Ofek G, McKee K, Yang Y, Yang ZY, Skinner J, Guenaga FJ, Wyatt R, Zwick MB, Nabel GJ, Mascola JR, Kwong PD: Relationship between antibody 2F5 neutralization of HIV-1 and hydrophobicity of its heavy chain third complementarity-determining region. J Virol 2010, 84:2955-2962.

doi:10.1186/s12967-014-0346-3

Cite this article as: Miglietta et al: Synergy in monoclonal antibody neutralization of HIV-1 pseudoviruses and infectious molecular clones. Journal of Translational Medicine 2014 12:346.

\section{Submit your next manuscript to BioMed Central and take full advantage of:}

- Convenient online submission

- Thorough peer review

- No space constraints or color figure charges

- Immediate publication on acceptance

- Inclusion in PubMed, CAS, Scopus and Google Scholar

- Research which is freely available for redistribution 